\title{
Disease characteristics and survival outcomes of extragonadal primary germ cell tumour in two Canadian tertiary cancer centres
}

\author{
Jenny J. Ko, MD; Tehmina Asif, MD; ${ }^{2}$ Haocheng Li, MD; Nimira Alimohamed, MD;4 Phuong Thao Nguyen, \\ $M D ;{ }^{5}$ Daniel Y.C. Heng, $M D^{4}$
}

'Department of Medical Oncology, Abbotsford Cancer Centre, Abbotsford, BC, Canada; 2 Department of Medical Oncology, Saskatchewan Cancer Agency, Saskatoon, SK, Canada; ${ }^{3}$ Departments of Oncology and Community Health Sciences, University of Calgary, Calgary, AB, Canada; ${ }^{4}$ Department of Medical Oncology, Tom Baker Cancer Centre, Calgary, AB, Canada; ${ }^{5}$ Department of Medical Oncology, Royal Inland Cancer Centre, Kamloops, BC, Canada

Cite as: Can Urol Assoc J 2016;10(5-6):E165-70. http://dx.doi.org/10.5489/cuaj.3357 Published online May 12, 2016.

\section{Abstract}

Introduction: Extragonadal germ cell tumours (EGCTs) are a heterogeneous group with distinct natural history and responses to treatment modalities. We sought to evaluate characteristics and survival outcomes in men with EGCTs.

Methods: We performed a retrospective analysis on a consecutive list of men diagnosed with EGCT in two Albertan cancer centres between 1990 and 2013. Demographic characteristics and outcomes, stratified by primary site, were evaluated.

Results: Sixty-nine cases were identified. The median age was 29 (range 15-76) and 48 cases (70\%) were non-seminomatous. Twenty-four (35\%) belonged to International Germ Cell Cancer Collaborative Group (IGCCCG) favourable risk group, $14(20 \%)$ to intermediate, and 31 (45\%) to poor. Thirty (43\%) had mediastinal primary (MPs); 29 were treated with first-line bleomycin, etoposide, and cisplatin (BEP). Seventeen (57\%) relapses occurred, of which three patients achieved long-term survival. Seventeen (25\%) had a central nervous system (CNS) primary, with eight $(47 \%)$ classic germinoma. Seven (41\%) received primary chemotherapy alone; 5 (29\%) received primary radiotherapy alone, and $5(29 \%)$ received both. Nineteen $(28 \%)$ had a retroperitoneal primary (RPs) and received first-line chemotherapy; all but two received BEP and eight $(42 \%)$ had surgical resection. Three $(5 \%)$ had other or unknown primary. Five-year overall survival (OS) and disease-free survival for all patients were $56 \%$ and $44 \%$, respectively; for MPs, $44 \%$ and $34 \%$; for CNS primary, $76 \%$ and $53 \%$; for RPs, $58 \%$ and $53 \%$. Factors that correlated with decreased OS were elevated alpha fetoprotein $(A F P)(p<0.001)$ or human chorionic gonadotropin (HCG) $(p=0.001)$, lactate dehydrogenase $(\mathrm{LDH})$ levels $(p=0.028)$, bone metastasis $(p<0.001)$, lung metastasis $(p<0.001)$, and IGCCCG poor risk $(\mathrm{p}=0.001)$.

Conclusions: EGCT is a rare, but important subset of GCT. Patients with EGCTs, despite aggressive treatments, still have poorer outcomes than gonadal primary.

\section{Introduction}

Extragonadal germ cell tumours (EGCTs) comprise a heterogeneous group of primary germ cell tumours with distinct natural history and responses to different treatment modalities. The incidence of EGCTs is estimated at 1.9-3.4/1 000 000. ${ }^{1}$ EGCTs often occur in the midline of the body, with the three most common sites in the anterior mediastinum, retroperitoneum, and pineal gland. ${ }^{1,2}$ Epidemiologic studies suggest that although similar in morphologic appearance, the embryonic and genetic initiating events of EGCTs may be distinct from the gonadal germ cell tumours (GGCTs). ${ }^{1-4}$ EGCTs, especially of the mediastinal origin, are often marked by inferior survival outcomes compared to GGCTs, as well as hematologic neoplasms (acute myeloid leukemia and malignant histiocytosis) and systemic mast cell disease that are unrelated to treatment effect. ${ }^{5,6}$

The usual treatment for EGCTs has been platinum-based chemotherapy regimen, such as bleomycin, etoposide and cisplatin (BEP), followed by surgical resection of residual tumours, if feasible. ${ }^{7}$ Previously published retrospective studies have suggested efficacy of chemotherapy in achieving complete response and long-term survival in both seminomatous and non-seminomatous germ cell tumours of extragonadal origin. ${ }^{8-12}$ Patients with relapse can be salvaged with high-dose chemotherapy with stem cell support similar to disease relapse in GGCTs, although prospective, randomized data are lacking. ${ }^{13,14}$ There is substantial variability in the case volume and surgical expertise among centres and a multidisciplinary care in a specialized tertiary cancer centre is essential in the treatment of EGCTs. ${ }^{7,15}$ Even with optimal treatments, survival varies among different primary sites and can range from five-year survival of $30-40 \%$ in the mediastinal EGCTs to $90 \%$ in germinoma of the central nervous system. ${ }^{4,11,16,17}$ To date, however, published data on the treatment of EGCTs in Canadian patients are scarce. 
Ko et al.

The objectives of our study were to evaluate patient, disease, and treatment characteristics and survival outcomes in male patients diagnosed with EGCTs in two Canadian tertiary cancer centres.

\section{Methods}

We performed a retrospective analysis on a consecutive list of all male patients diagnosed with EGCT and treated in Alberta. All cases of GCTs in the two tertiary cancer centres (Tom Baker Cancer Centre, Calgary, AB; Cross Cancer Institute, Edmonton, $\mathrm{AB}$ ) were reviewed; all consecutive cases in which treating physicians made the diagnosis of and proceeded with treatments for EGCT were included. All cases underwent attempts at pathologic diagnosis with either fine-needle, core-needle or excisional biopsy; 17 patients had non-diagnostic pathology and were diagnosed and treated as EGCT based on tumour markers or clinical presentation. Electronic and paper charts were obtained and reviewed by the study coordinators using the pre-specified data template. Data for patients treated in Edmonton were only available between January 1, 2002 and December 31, 2010, while all data were accessible for patients treated in Calgary between January 1, 1990 and December 31, 2013. Disease relapse was determined if there was a rise in tumour markers or radiologic progression after the first-line curative therapy was finished; post-chemotherapy resection of residual tumour was considered to be part of the first-line therapy and was not counted as relapse.

Data were transferred from Excel to Stata S/E Version 13 for analysis. Categorical variables were expressed as a frequency and percentage; patient age was expressed as mean and range. Overall survival (OS) was defined as the date of diagnosis to the date of death or last followup visit, with patients censored at their last followup visit. Diseasefree survival (DFS) was defined as the date of diagnosis to the date of relapse, progression, death, or last followup visit and similarly censored at last followup visit. OS and DFS curves in the entire cohort and the following subgroups, stratified by the primary site, were estimated by KaplanMeier method with log-rank test to compare the differences among central nervous system (CNS), mediastinal (MP), and retroperitoneal primary (RP) sites. Hazard ratios for the risk group stratification (e.g. International Germ Cell Cancer Collaborative Group [IGCCCG]) were modeled by univariate Cox regression. A p value $<0.05$ was considered to be statistically significant.

\section{Results}

Between 1990 and 2013, 69 patients in two Albertan tertiary cancer centres were diagnosed with EGCT. Table 1 summarizes patient, disease and treatment characteristics for all patients, as well as three subgroups stratified by primary site. Among 30 patients $(43 \%)$ with MPs with $\geq 5$ years of followup, 5/8 patients (63\%) with seminomatous and 6/19 (32\%) with non-seminomatous MPs achieved long-term survival. One patient died due to bleomycin lung toxicity after two cycles of BEP. Upfront or salvage high-dose chemotherapy with autologous stem cell support was used in 11 patients, of which three $(27 \%)$ survived $\geq 5$ years. Seventeen $(57 \%)$ relapses occurred; most were high-risk $(n=2,13 \%)$ or very high-risk ( $n=15,87 \%$ ) by the IGCCCG2 criteria. $^{18}$ Fifteen $(88 \%)$ received salvage chemotherapy with $(n=1)$ or without $(n=14)$ radiation therapy $(R T)$, most commonly paclitaxel, ifosfamide and cisplatin (TIP) $(n=8)$. Other regimens included upfront salvage high-dose chemotherapy with stem cell support $(n=3), B E P(n=2)$, and vinblastine, ifosfamide and cisplatin (VelP, $\mathrm{n}=2$ ). Two patients had resection of residual mass after salvage therapy, all of which contained viable non-teratomatous GCTs. Three patient $(20 \%)$ with relapse achieved long-term survival.

Seventeen patients (25\%) had a CNS primary, of which eight $(47 \%)$ were classic germinoma; five $(29 \%)$ had IGCCCG intermediate- or poor-risk disease. Seven (41\%) received primary chemotherapy alone; five (29\%) received primary RT alone; five (29\%) patients received both. Among those with $\geq 5$ years of followup, $6 / 7$ patients ( $86 \%$ ) with CNS germinoma and 5/8 (63\%) with non-seminomatous CNS primary achieved long-term survival. One patient passed away due to possible bleomycin lung toxicity five months after BEP regimen. Five patients (29\%) relapsed, of whom three patients $(60 \%)$ achieved long-term survival.

Nineteen patients $(28 \%)$ had a RP. Five $(26 \%)$ were accompanied by other visceral or mediastinal lymph node metastases. Most ( $n=15,79 \%$ ) had non-seminoma. All received first-line chemotherapy; all but two received BEP. Eight $(42 \%)$ patients had upfront or salvage surgical resection, seven of which were found with viable tumour. All eight patients $(42 \%)$ who relapsed had non-seminoma and died within one year of relapse. None of the RP patients received salvage high-dose chemotherapy with autologous stem cell support at the time of the first recurrence; only one patient received salvage high-dose chemotherapy after salvage chemotherapy failure, but eventually died from relapse. The most common salvage therapy was TIP $(n=3)$, followed by VelP $(n=2)$, etoposide (EP) $(n=1)$, and upfront salvage high-dose chemotherapy with stem cell support $(n=1)$.

Lastly, three patients $(5 \%)$ had other $(n=1$ for prostate, $n=1$ for intraperitoneal) or unknown primary $(n=1)$. The patient with the prostate seminomatous primary achieved long-term complete remission (CR) after first-line chemotherapy, while the other two passed away despite treatment.

The Kaplan-Meier curves of OS and DFS, stratified by the IGCCCG risk groups, are shown in Fig. 1. One patient is excluded for losing followup information. The five-year 


\begin{tabular}{|c|c|c|c|c|}
\hline Variable & Overall (n=69) & Mediastinal $(n=30)$ & CNS (n=17) & Retroperitoneal $(n=19)$ \\
\hline Age (range) & $29(15-76)$ & $29(16-55)$ & $21(15-51)$ & $39(21-76)$ \\
\hline \multicolumn{5}{|l|}{ IGCCCG risk groups } \\
\hline Favourable & $24(35 \%)$ & 0 & $12(71 \%)$ & $10(53 \%)$ \\
\hline Intermediate & $14(20 \%)$ & $9(30 \%)$ & $1(6 \%)$ & $4(21 \%)$ \\
\hline Poor & $31(45 \%)$ & $21(70 \%)$ & $4(23 \%)$ & $5(26 \%)$ \\
\hline \multicolumn{5}{|l|}{ Tumour characteristics } \\
\hline Seminoma & $21(30 \%)$ & $9(30 \%)$ & $8(47 \%)$ & $4(21 \%)$ \\
\hline Non-seminoma & $48(70 \%)$ & $21(70 \%)$ & $9(53 \%)$ & $15(79 \%)$ \\
\hline Primary tumour size, median in $\mathrm{cm}$ (range) & $9(1.5-26)$ & $12(5-22)$ & $3(1.5-4)$ & $10(2-26)$ \\
\hline \multicolumn{5}{|l|}{ Tumour markers } \\
\hline Elevated alpha-fetoprotein & $23(33 \%)$ & $17(57 \%)$ & $3(18 \%)$ & $3(16 \%)$ \\
\hline $\begin{array}{l}\text { Elevated beta-human chorionic } \\
\text { gonadotropin }\end{array}$ & $22(32 \%)$ & $13(43 \%)$ & $1(6 \%)$ & $7(37 \%)$ \\
\hline Elevated lactate dehydrogenase & $22(32 \%)$ & $12(40 \%)$ & $4(23 \%)$ & $6(32 \%)$ \\
\hline \multicolumn{5}{|l|}{ Treatments } \\
\hline Surgical resection & $25(36 \%)$ & $15(50 \%)$ & $2(12 \%)$ & $8(42 \%)$ \\
\hline First-line chemotherapy & $64(93 \%)$ & $30(100 \%)$ & $12(71 \%)$ & $19(100 \%)$ \\
\hline BEP & $53(77 \%)$ & $29(97 \%)$ & $5(29 \%)$ & 17 (89\%) \\
\hline Bleomycin lung toxicity & $10 / 53(19 \%)$ & $4 / 29(14 \%)$ & $1 / 5(20 \%)$ & $4 / 17(24 \%)$ \\
\hline First-line RT & $15(22 \%)$ & $3(10 \%)$ & $10(59 \%)$ & $2(11 \%)$ \\
\hline \multicolumn{5}{|l|}{ Relapse } \\
\hline Patients with relapse & $32(46 \%)$ & $17(57 \%)$ & $5(29 \%)$ & $8(42 \%)$ \\
\hline \multicolumn{5}{|l|}{ Prognostic score at relapse $\left(\right.$ IGCCCG2) ${ }^{18}$} \\
\hline Very low & 0 & 0 & 0 & 0 \\
\hline Low & $1(3 \%)$ & 0 & 0 & $1(13 \%)$ \\
\hline Intermediate & $5(16 \%)$ & 0 & $2(40 \%)$ & $3(37 \%)$ \\
\hline High & $4(12 \%)$ & $2(12 \%)$ & $2(40 \%)$ & 0 \\
\hline Very high & $22(69 \%)$ & $15(88 \%)$ & $1(20 \%)$ & $4(50 \%)$ \\
\hline \multicolumn{5}{|l|}{ Treatments } \\
\hline Salvage chemotherapy & $25(78 \%)$ & $15(88 \%)$ & $2(40 \%)$ & $7(88 \%)$ \\
\hline Salvage radiation therapy & $8(25 \%)$ & $3(18 \%)$ & $2(40 \%)$ & $2(25 \%)$ \\
\hline $\begin{array}{l}\text { High-dose chemotherapy with } \\
\text { autologous stem cell support }\end{array}$ & $6(19 \%)$ & $5(29 \%)$ & $1(20 \%)$ & 0 \\
\hline
\end{tabular}

OS (5YOS) and DFS (5YDFS) for all patients were $56 \%$ and $44 \%$, respectively. The 5 YOS and DFS for MPs were $44 \%$ and $34 \%$, respectively; for CNS primary, $76 \%$ and $53 \%$; for RPs, 58\% and 53\% (Fig. 2). Significant differences among the 5 YOS $(p=0.006)$ and 5 YDFS $(p=0.002)$ were noted among different primary sites, with the CNS primary showing the best survival and MP, worst. The factors that correlated with OS were elevated alpha fetoprotein (AFP) $(p=<0.001)$ and/ or human chorionic gonadotropin (HCG) levels $(p=0.001$ ), lactate dehydrogenase $(\mathrm{LDH})$ levels $(\mathrm{p}=0.028)$, lung metastasis $(p=<0.001)$, bone metastasis $(p=<0.001)$, and IGCCCG risk group $(\mathrm{p}=0.001)$.

\section{Discussion}

To the authors' knowledge, our study comprises the largest published Canadian cohort of patients with EGCTs to date.
Goss et al previously published a single-institution experience of 37 patients with EGCTs treated in a tertiary cancer centre in Toronto, ON. ${ }^{19}$ The six-year OS for seminomatous EGCTs was $88 \%$, while for non-seminomatous EGCTs, 53\%. Our study shows a comparable results in all subgroups except in seminomatous MPs, with lower than expected 5 YOS of $63 \%$. Among the nine cases of seminomatous MPs in our cohort, three cases underwent resection of residual disease, which were fibrosis and/or necrotic tissues; four cases relapsed afterwards. This finding, despite the small number of patients, is unusual in gonadal seminoma. This may reflect inherent chemoresistance of MP-GCTs; however, unlike gonadal GCTs, in which orchiectomy specimens are obtained, tissue biopsies in MP-GCTs are typically inadequate and prone to potential sampling issues. Therefore, one hypothesis is that there is some degree of misclassification of non-seminoma into seminoma. While the same may be true for other EGCTs, we did 
Ko et al.

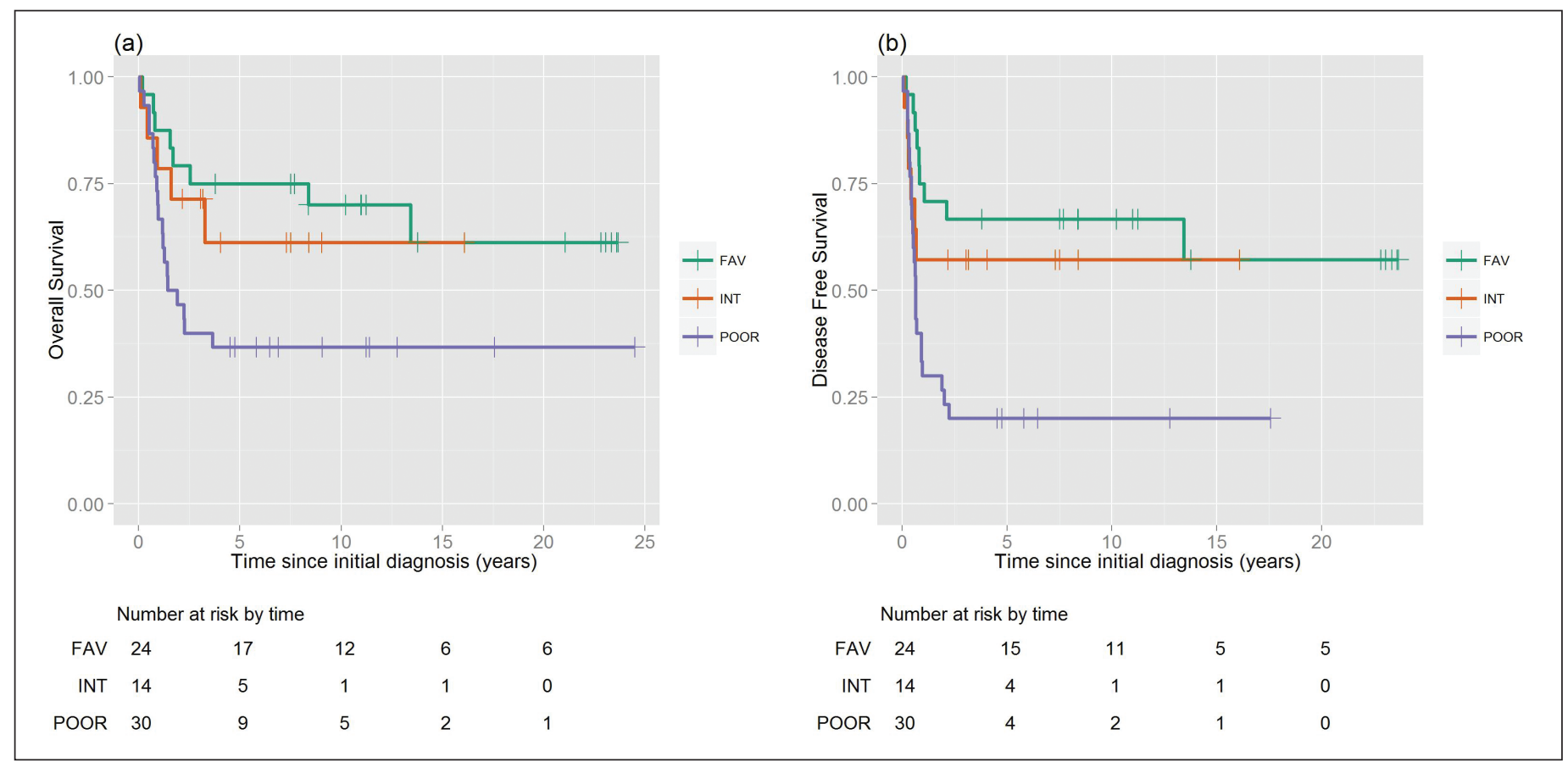

Fig. 1. Kaplan-Meier curve of (a) overall survival and (b) disease-free survival, for the overall cohort. X-axis in months; FAV: IGCCCG favourable risk group; INT: intermediate risk group; P0OR: poor risk group.

not note significant discrepancy between our outcomes and those reported in the literature for other primary sites when stratified by seminoma vs. non-seminoma except in MPs.

Our results showed that the outcomes of EGCTs remain inferior to those of GGCTs, even in RP and CNS primary.
This is contrary to other smaller studies that show generally favourable prognosis for RP and CNS GCTs. ${ }^{15,20,21}$ However, these studies included too few non-seminomatous RP or CNS primary to make a meaningful comparison to our cohort. Larger studies, on the other hand, showed that $88 \%$ of

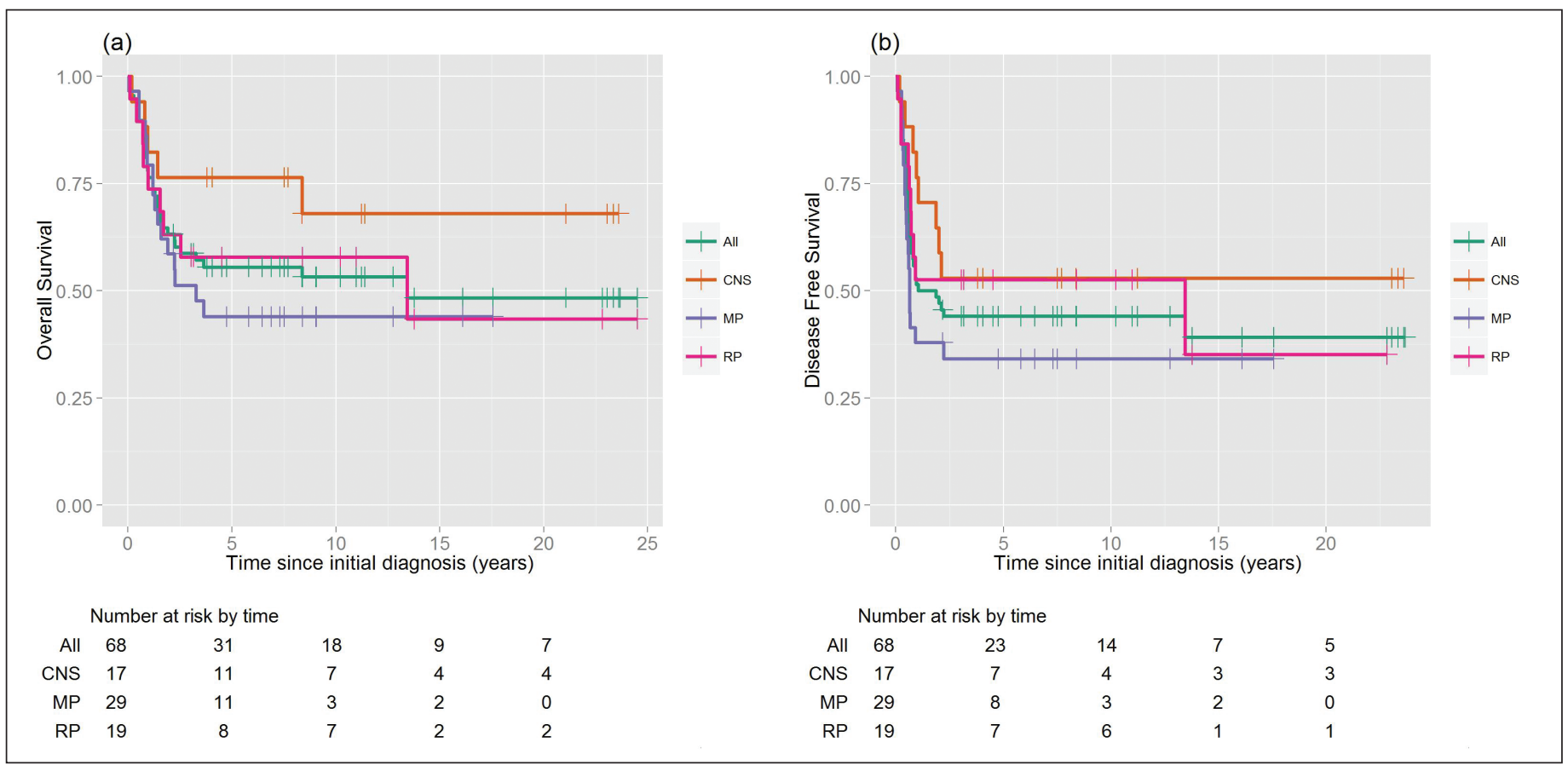

Fig. 2. Kaplan-Meier curve of the overall survival (a) and disease-free survival (b), for the overall cohort and subgroups by primary site; $X$-axis in months; All: all patients with EGCT; CNS: intracranial primary GCT; MP: mediastinal primary GCT; RP: retroperitoneal primary GCT. 
seminomatous EGCTs, but only $45 \%$ of non-seminomatous EGCTs, achieved long-term DFS. ${ }^{11,17}$ Furthermore, patients with non-seminomatous RPs had survival just as poor as those with MPs, an intriguing finding given that there exists evidence that RPs may simply represent GGCTs with burntout gonadal primary. ${ }^{22,23}$ Inferior survival in EGCTs may be in part due to relative insensitivity to cisplatin-based chemotherapy and aggressive pathology inherent in EGCTs. For example, Pectasides et al showed that non-seminomatous EGCTs had a greater degree of p53, MIB-1, and COX-2 overexpression compared with matched cohorts of GGCTs and seminomatous EGCTs, demonstrating potential biologic differences. ${ }^{24}$ Recent large trials, such as EORTC 30983 and GETUG 13, reported improved DFS, but similar OS with more intensive chemotherapy regimens in patients with high-risk GGCT. ${ }^{25,26}$ More studies are needed to elucidate whether more intensive chemotherapy or targeted therapy can improve outcomes in patients with EGCTs.

Salvage therapy in our patients with relapsed disease, especially of RPs, also did not seem as effective as that reported in GGCT. In literature, about $19 \%$ of patients with recurrent EGCT achieve long-term DFS (11\% mediastinal, 30\% retroperitoneal). ${ }^{27}$ Our study included a high proportion of nonseminoma, especially in the retroperitoneal group, with less frequent use of high-dose chemotherapy with stem cell support. In our cohort, TIP was most frequently used for salvage chemotherapy, while VIP (etoposide, ifosfamide and cisplatin) or VelP regimens are commonly used in other centres, both as upfront and salvage therapy. ${ }^{27,28} \mathrm{Also}$, none of our patients with RPs received high-dose chemotherapy with stem cell support after first relapse, perhaps due to a perception that salvage chemotherapy may be sufficient for relapse. However, most of our patients who had salvage surgery had viable nonteratomatous malignancy in the surgical pathology. Given these findings, for selected patients with MP- and RP-GCTs who relapse - especially within one year of first-line therapy - aggressive, upfront salvage therapies, such as high-dose chemotherapy with stem cell support, may be appropriate.

Our results confirm the rates of bleomycin lung toxicity in $15-30 \%$ of the patients treated with BEP, similar to those reported in GGCT patients (0-46\%). ${ }^{29-31}$ Importantly, three patients had Grade 3-5 respiratory failure, possibly due to bleomycin exposure, with no clear risk factors otherwise. In our study, almost all patients with MPs and RPs received BEP as first-line therapy. While the BEP regimen is the standard of care in GGCTs and is most established in the management of EGCTs, there is some evidence to suggest that this regimen may interfere with optimal surgical management and postoperative outcomes due to bleomycin-related lung toxicity. For example, in a large case series of surgical resection of residual disease in the EGCT patients, Kesler et al reported that nine of 10 patients who had postoperative mortality and nine of 26 patients who experienced postoperative complications were attributed to respiratory failure from bleomycin. ${ }^{32}$ None of the patients who received chemotherapy regimens other than BEP had respiratory complications. This finding underscores the importance of bleomycin avoidance in patients with potential risk factors for respiratory failure or anticipated surgical resection of residual tumours.

In our cohort with CNS primary, there were seven cases of complete response and long-term survival with first-line chemotherapy alone without RT or surgical resection. CNS GCTs comprise a unique group of GCTs, with no uniform standards of care. In particular, our cohort contained a large proportion of suspected or confirmed non-germinoma. Data on non-germinomatous CNS tumours, including evidence for optimal treatment, are lacking due to their rarity and difficulties in accurate histopathologic diagnosis. ${ }^{33,34}$ Generally accepted treatments include radiation therapy with or without chemotherapy, with favourable survival in classic germinoma, but less favourable in mixed histopathology. ${ }^{35-37}$ At least one study reports a favourable prognosis and germinoma-like pathology in patients who achieve complete response with chemotherapy, but it is unknown whether a combined modality is superior to a single modality treatment. ${ }^{38}$ Even though in vitro studies have shown therapeutic concentrations of bleomycin and etoposide, the penetration of cisplatin into the intracranial space is limited. ${ }^{39-41}$ Further studies are needed to clarify the role of first-line radiation and chemotherapy in primary CNS GCTs.

\section{Conclusion}

In summary, EGCT is a rare, but important subset of GCTs. Patients with EGCT, in particular non-seminomatous, have poorer outcomes compared with gonadal primary despite aggressive treatments. Non-seminomatous EGCTs demonstrate relative chemo-resistance and further studies are needed to identify optimal upfront and salvage treatment options.

Competing interests: Dr. Ko has received honoraria from Janssen. Dr. Alimohamed has received honoraria from Astellas and Bayer. Dr. Heng has been an Advisory Board member for Bayer, GSK, Novartis, and Pfizer. The remaining authors declare no competing financial or personal interests.

This paper has been peer-reviewed.

\section{References}

1. Stang A, Trabert B, Wentzensen N, et al. Gonadal and extragonadal germ cell tumours in the United States, 1973-2007. Int J Androl 2012;35:616-25. http://dx.doi.org/10.1111/i.1365-2605.2011.01245.x

2. Rusner $C$, Trabert $B$, Katalinic $A$, et al. Incidence patterns and trends of malignant gonadal and extragonadal germ cell tumours in Germany, 1998-2008. Cancer Epidemiol 2013;37:370-3.http://dx.doi. org/10.1016/i.canep.2013.04.003 
Ko et al.

3. Arora RS, Alston RD, Eden TO, et al. Comparative incidence patterns and trends of gonadal and extragonadal germ cell tumours in England, 1979 to 2003. Cancer 2012;118:4290-97. http://dx.doi.org/10.1002/ cncr.27403

4. McKenney JK, Heerema-McKenney A, Rouse RV. Extragonadal germ cell tumours: A review with emphasis on pathologic features, clinical prognostic variables, and differential diagnostic considerations. Adv Anat Pathol 2007;14:69-92. http://dx.doi.org/10.1097/PAP.0b013e31803240e6

5. Fizazi K, Culine S, Droz JP, et al. Primary mediastinal non-seminomatous germ-cell tumours: From clinics to biology. Bull Cancer 1997;84:313-27.

6. International Germ Cell Consensus Classification: A prognostic factor-based staging system for metastatic germ cell cancers. International Germ Cell Cancer Collaborative Group. J Clin Oncol 1997;15:594-603.

7. Schmoll HJ, Souchon R, Krege S, et al. European consensus on diagnosis and treatment of germ cell cancer: A report of the European Germ Cell Cancer Consensus Group (EGCCCG). Ann Oncol 2004;15:1377-99. http://dx.doi.org/10.1093/annonc/mdh301

8. Hartmann JT, Nichols CR, Droz JP, et al. Prognostic variables for response and outcome in patients with extragonadal germ-cell tumours. Ann Oncol 2002;13:1017-28. http://dx.doi.org/10.1093/annonc/ mdf176

9. Pectasides D, Aravantinos $G$, Visvikis $A$, et al. Platinum-based chemotherapy of primary extragonadal germ cell tumours: The Hellenic Cooperative Oncology Group experience. Oncology 1999;57:1-9. hittp:// dx.doi.org/10.1159/000011993

10. Billmire D, Vinocur C, Rescorla F, et al. Malignant mediastinal germ cell tumours: An intergroup study. J Pediatr Surg 2001;36:18-24. http://dx.doi.org/10.1053/ipsu.2001.19995

11. Bokemeyer C, Droz JP, Horwich A, et al. Extragonadal seminoma: An international multicentre analysis of prognostic factors and long-term treatment outcome. Cancer 2001;91:1394-401. http://dx.doi. org/10.1002/1097-0142(20010401)91:7<1394::AID-CNCR1 144>3.0.C0;2-Y

12. Schneider BP, Kesler KA, Brooks JA, et al. Outcome of patients with residual germ cell or non-germ cell malignancy after resection of primary mediastinal nonseminomatous germ cell cancer. J Clin Oncol 2004;22:1195-200. http://dx.doi.org/10.1200/JC0.2004.07.102

13. Kumano $M$, Miyake $H$, Hara I, et al. First-line high-dose chemotherapy combined with peripheral blood stem cell transplantation for patients with advanced extragonadal germ cell tumours. Int J Urol 2007;14:336-8. http://dx.doi.org/10.1111/j.1442-2042.2006.01718.x

14. Rosti $G$, De Giorgi U, Wandt $H$, et al. First-line high-dose chemotherapy for patients with poor prognosis extragonadal germ cell tumours: The experience of the European Bone Marrow Transplantation (EBMT) Solid Tumours Working Party. Bone Marrow Transplant 2004;34:1033-7. http://dx.doi.org/10.1038/ si.bmt. 1704704

15. Andac A, Mert B, Sevil B, et al. Adult primary extragonadal germ cell tumours: Treatment results and long-term followup. Med Pediatr Oncol 2003;41:49-53. http://dx.doi.org/10.1002/mpo.10136

16. Hsu YJ, Pai L, Chen YC, et al. Extragonadal germ cell tumours in Taiwan: An analysis of treatment results of 59 patients. Cancer 2002;95:766-74. http://dx.doi.org/10.1002/cncr.10738

17. Bokemeyer C, Nichols CR, Droz JP, et al. Extragonadal germ cell tumours of the mediastinum and retroperitoneum: Results from an international analysis. J Clin Oncol 2002;20:1864-73. http://dx.doi. org/10.1200/JC0.2002.07.062

18. International Prognostic Factors Study G, Lorch A, Beyer J, et al. Prognostic factors in patients with metastatic germ cell tumours who experienced treatment failure with cisplatin-based first-line chemotherapy. $J$ Clin Oncol 2010;28:4906-11. http://dx.doi.org/10.1200/JC0.2009.26.8128

19. Goss PE, Schwerffeger L, Blackstein ME, et al. Extragonadal germ cell tumours. A 14-year Toronto experience. Cancer 1994;73:1971-9. http://dx.doi.org/10.1002/1097-0142(19940401)73:7<1971::AlDCNCR2820730731>3.0.C0;2-A

20. Berkmen F, Peker AF, Ayyildiz A, et al. Extragonadal germ cell tumours: Clinicopathologic findings, staging and treatment experience in 14 patients. J Exp Clin Cancer Res 2000;19:281-5.

21. Ganjoo KN, Rieger KM, Kesler KA, et al. Results of modern therapy for patients with mediastinal nonseminomatous germ cell tumours. Cancer 2000;88:1051-6. http://dx.doi.org/10.1002/(SICI) 1097 0142(20000301)88:5<1051::AID-CNCR15>3.0.C0;2-R

22. Bokemeyer $C$, Hartmann JT, Fossa SD, et al. Extragonadal germ cell tumours: Relation to testicular neoplasia and management options. APMIS 2003;111:49-59;discussion 59-63. http://dx.doi. org/10.1034/i.1600-0463.2003.11101081.x
23. Punjani N PN. Do retroperitoneal extragonadal germ cell tumours exist? Paper presented at: Canadian Urological Association Annual Meeting; Tuesday June 30, 2015; Ottawa, ON.

24. Pectasides $D$, Valavanis $C$, Nikolaou $M$, et al. Molecular markers in extragonadal germ cell tumours: A matched case-control study. Histopathology 2007;50:394-6. http://dx.doi.org/10.1111/j.13652559.2007.02587.x

25. Fizazi K, Pagliaro L, Laplanche A, et al. Personalized chemotherapy based on tumour marker decline in poor prognosis germ-cell tumours (GETUG 13): A phase 3, multicentre, randomized trial. Lancet Oncol 2014;15:1442-50. http://dx.doi.org/10.1016/S1470-2045(14)70490-5

26. de Wit R, Skoneczna I, Daugaard G, et al. Randomized phase III study comparing paclitaxel-bleomycin, etoposide, and cisplatin (BEP) to standard BEP in intermediate-prognosis germ-cell cancer: Intergroup study EORTC 30983. J Clin Oncol 2012;30:792-9. http://dx.doi.org/10.1200/JC0.2011.37.0171

27. Hartmann JT, Einhorn L, Nichols CR, et al. Second-line chemotherapy in patients with relapsed extragonadal nonseminomatous germ cell tumours: Results of an international multicenter analysis. J Clin Oncol 2001;19:1641-8.

28. De Giorgi U, Demirer $\mathrm{T}$, Wandt $\mathrm{H}$, et al. Second-line high-dose chemotherapy in patients with mediastinal and retroperitoneal primary non-seminomatous germ cell tumours: The EBMT experience. Ann Oncol 2005; 16:146-51. http://dx.doi.org/10.1093/annonc/mdi017

29. Azambuja E, Fleck JF, Batista RG, et al. Bleomycin lung toxicity: Who are the patients with increased risk? Pulm Pharmacol Ther 2005;18:363-6. http://dx.doi.org/10.1016/i.pupt.2005.01.007

30. Levi JA, Raghavan $D$, Harvey $V$, et al. The importance of bleomycin in combination chemotherapy for good-prognosis germ cell carcinoma. Australasian Germ Cell Trial Group. J Clin Oncol 1993; 11:1300-5.

31. Dearnaley DP, Horwich A, A'Hern R, et al. Combination chemotherapy with bleomycin, etoposide and cisplatin (BEP) for metastatic testicular teratoma: Long-term followup. Eur J Cancer 1991;27:684-91. http://dx.doi.org/10.1016/0277-5379(91)90166-B

32. Kesler KA, Rieger KM, Hammoud ZT, et al. A 25-year single institution experience with surgery for primary mediastinal nonseminomatous germ cell tumours. Ann Thorac Surg 2008:85:371-8. http://dx.doi. org/10.1016/j.athoracsur.2007.09.020

33. Gao Y, Jiang J, Liu Q. Clinico-pathological and immunohistochemical features of primary central nervous system germ cell tumours: A 24-year experience. Int I Clin Exp Pathol 2014;7:6965-72.

34. Lee D, Suh YL. Histologically confirmed intracranial germ cell tumours: An analysis of 62 patients in a single institute. Virchows Arch 2010;457:347-57. hitp://dx.doi.org/10.1007/s00428-010-0951-3

35. Westphal M, Emami P. Pineal lesions: A multidisciplinary challenge. Adv Tech Stand Neurosurg 2015;42:79-102. http://dx.doi.org/10.1007/978-3-319-09066-5_5

36. Kawabata Y, Takahashi JA, Arakawa Y, et al. Long-term outcomes in patients with intracranial germinomas: A single-institution experience of irradiation with or without chemotherapy. J Neurooncol 2008;88:161-7. http://dx.doi.org/10.1007/s 11060-008-9542-4

37. Paximadis $P$, Hallock $A$, Bhambhani $K$, et al. Patterns of failure in patients with primary intracranial germinoma treated with neoadjuvant chemotherapy and radiotherapy. Pediatr Neurol 2012;47:162-6. http://dx.doi.org/10.1016/i.pediatrneurol.2012.05.025

38. Saito R, Kumabe T, Kanamori M, et al. Early response to chemotherapy as an indicator for the management of germinoma-like tumours of the pineal and/or suprasellar regions. J Clin Neurosci 2014;21:124-30. http://dx.doi.org/10.1016/i.jocn.2013.05.014

39. Jacobs S, MCCully CL, Murphy RF, et al. Extracellular fluid concentrations of cisplatin, carboplatin, and oxaliplatin in brain, muscle, and blood measured using microdialysis in nonhuman primates. Cancer Chemother Pharmacol 2010;65:817-24. http://dx.doi.org/10.1007/s00280-009-1085-7

40. Relling MV, Mahmoud HH, Pui CH, et al. Etoposide achieves potentially cytotoxic concentrations in CSF of children with acute lymphoblastic leukemia. J Clin Oncol 1996;14:399-404.

41. Donelli $M G$, Zucchetti $M, D^{\prime}$ Incalci $M$. Do anticancer agents reach the tumor target in the human brain? Cancer Chemother Pharmacol 1992;30:251-60. http://dx.doi.org/10.1007/BF00686291

Correspondence: Dr. Daniel Y.C. Heng, Tom Baker Cancer Centre, Calgary, AB, Canada; Daniel.Heng@albertahealthservices.ca 